\title{
Effects of insulin on in vitro vascular cell adhesion molecule-1 expression and in vivo soluble VCAM-1 release
}

\author{
G. De Mattia ${ }^{1}$, M.C. Bravi ${ }^{2}$, A. Costanzo $^{1}$, O. Laurenti $^{1}$, M. Cassone Faldetta ${ }^{2}$, A. Armiento ${ }^{1}$, O. De Luca ${ }^{1}$, \\ C. Ferri ${ }^{1}$ \\ ${ }^{1}$ University "La Sapienza”, Andrea Cesalpino Foundation, Rome, Italy \\ ${ }^{2}$ University of L'Aquila, Department of Internal Medicine, L'Aquila, Italy
}

\section{Abstract}

Aims/hypothesis. To evaluate the effects of insulin on vascular cell adhesion molecule-1 expression by cultured human vascular endothelial cells and soluble vascular cell adhesion molecule-1 release in vivo.

Methods. Human vascular endothelial cells derived from umbilical cord veins were incubated with either insulin (from $10^{-6}$ to $10^{-9} \mathrm{~mol} / \mathrm{l}$ ) or tumour necrosis factor- $\alpha(5 \mathrm{ng} / \mathrm{ml})$ for 6 to $24 \mathrm{~h}$. Plasma soluble vascular cell adhesion molecule-1 concentrations were evaluated in 12 non-insulin-dependent diabetic patients ( 8 men, 4 women, mean age $47.1 \pm 7.7$ years) and 12 healthy volunteers matched for age, sex and weight (7 men, 5 women, mean age $42.2 \pm 7.2$ years) before and after a 2-h euglycaemic hyperinsulinaemic clamp. Results. Transcriptional activities of nuclear factor- $\varkappa \mathrm{B}$ luciferase and vascular adhesion molecule-1 luciferase statistically significantly increased after incubation with tumour necrosis factor- $\alpha$. By contrast, a slight increment of nuclear factor- $\varkappa \mathrm{B}$ luciferase (mean: $1.8 \pm 0.3$ fold) but not of vascular cell adhesion mole- cule-1 luciferase transcriptional activities were detected in cells stimulated with insulin. Soluble vascular cell adhesion molecule- 1 concentrations in cell supernatants increased after tumour necrosis factor- $\alpha$ but not insulin stimulation. In vivo, baseline plasma soluble vascular cell adhesion molecule-1 concentrations were higher $(p=0.03)$ in non-insulin-dependent patients $(708.7 \pm 97.4 \mu \mathrm{g} / \mathrm{l})$ than controls $(632.1 \pm 65.2 \mu \mathrm{g} / \mathrm{l})$ but were not related to fasting insulin concentrations and did not change during insulin infusion.

Conclusion/interpretation. The increased concentrations of circulating soluble vascular cell adhesion molecule- 1 indicates that the vascular endothelium is activated in non-insulin dependent diabetic patients. Our in vitro and in vivo findings show that vascular cell adhesion molecule-1 activation cannot be due to hyperinsulinaemia. [Diabetologia (1999) 42: 1235-1239]

Keywords Insulin, adhesion molecules, endothelium, vascular cell adhesion molecule-1, non-insulin-dependent diabetes mellitus.
Although hyperinsulinaemia is an independent risk factor for the development of atherosclerotic lesions [1], mechanisms underlying the atherogenetic actions of insulin are largely unclear. Recent stud-

Received: 1 March 1999 and in revised form: 29 April 1999

Corresponding author: G. De Mattia, MD, Università "La Sapienza", Cattedra di I Clinica Medica, Fondazione Andea Cesalpino, I-00161 Roma, Italy

Abbreviations: VCAM-1, Vascular cell adhesion molecule$1 ; \mathrm{HUVEC}$, human umbilical vein endothelial cell; NF- $x \mathrm{~B}$, nuclear factor- $\varkappa \mathrm{B}$ ies have shown that insulin exerts various endothelial effects, such as an increase of endothelin-1 and nitric oxide production [2]. These findings are of particular relevance and suggest insulin might also exert other endothelial effects which, in turn, could trigger and maintain the atherogenetic process.

In this context, vascular cell adhesion molecule $(V C A M)-1$ is an endothelial adhesin whose up regulation is the most important initiating event in atheroma formation [3]. In spite of this, whether or not insulin might influence $V C A M-1$ expression by the human vascular endothelium is notknown. 
The aim of this study was to investigate the effects of insulin on $V C A M-1$ expression by human vascular endothelial cells derived from human umbilical cord veins (HUVECs). In this regard, cytokine-induced $V C A M-1$ expression is tightly transcriptionally regulated and requires the activation and nuclear translocation of nuclear factor $-x \mathrm{~B}(\mathrm{NF}-\varkappa \mathrm{B})$, i.e. a cytoplasmic multisubunit transcription factor which is essential to induce $V C A M-1$ promoter gene activation as well as interferon- $\beta$ regulatory factor- 1 [4]. Activation of NF- $x \mathrm{~B}$ by insulin has been reported in Chinese hamster ovary cells overexpressing wild-type insulin receptors [5]. Thus, in our experiments we used two different promoter-reporter gene constructs (an $\mathrm{NF}-x \mathrm{~B}$ and a $V C A M-1$ reporter) to study the effects of insulin on $V C A M-1$ transcriptional activation. In addition, because expression of $V C A M-1$ associated with membrane by $H U V E C s$ which have been activated by cytokine is associated with the release of its soluble form, soluble $V C A M-1$ concentrations are usually considered as a marker of $V C A M-1$ expression [6]. Consequently, we also evaluated the effects of insulin on soluble $V C A M-1$ release by cultured $H U V E C S$ as well as plasma soluble VCAM-1 concentrations in non-insulin dependent diabetic patients and healthy volunteers, before and after 2-h euglycaemic hyperinsulinaemic clamp studies.

\section{Methods}

\section{In vitro studies}

Cell cultures. Within $1 \mathrm{~h}$ from labour umbilical cord vein was incubated with $0.2 \%$ collagenase II at $37^{\circ} \mathrm{C}$ for $30 \mathrm{~min}$. Detached cells were flushed out by rinsing the cord vein thoroughly with medium199. Cells were pelleted and resuspended in Dulbecco's histone acetyl transferase medium before seeding on $35-\mathrm{mm}$ wells $(5 \mathrm{ml})$ containing this medium supplemented with fetal calf serum $(15 \%)$, penicillin $(100 \mathrm{u} / \mathrm{ml})$, streptomycin $(100 \mu \mathrm{g} / \mathrm{ml})$, L-glutamine $(2 \mathrm{mmol} / \mathrm{l})$ and endothelial cell growth factor $(10 \mathrm{ng} / \mathrm{ml})$ at $37^{\circ} \mathrm{C}$ in a humidified incubator ( $5 \%$ carbon dioxide in air). After 1 week of incubation, cells were resuspended in medium199 and then seeded again on gelatin-coated $35-\mathrm{mm}$ wells. After 5-6 days, cells reached confluency and the purity of cultures ( $>99 \%$ endothelial cells) was evaluated by fluorescence activated cell sorting after labelling with CD31.

Plasmids. The promoter-reporter gene constructs used in these studies included : NF- $\varkappa \mathrm{B}$ which contains two $\varkappa \mathrm{B}$ sites from the IgG kappa enhancer upstream of a luciferase encoding cDNA was a kind gift from Dr M. Karin (Dept of Pharmacology, UCSD, San Diego, Calif., USA) and VCAM-luciferase, kindly donated by Dr J. M. Redondo (Immunology Unit, Princess Hospital Madrid, Spain), which contains the $-519 /+120$ fragment of the VCAM-1 regulatory region upstream of a luciferase encoding cDNA in the pXP2-luciferase plasmid.

Transfections and measurements of reporter gene expression. Human umbilical vein endothelial cells were used after 2 to 4 passages. In particular, $1.8 \times 10^{5} H U V E C s$ were plated in 35-mm plates the day before transfection and transfected the next day with DNA using a cationic lipid-based reagent (Superfect, Qiagen, Germany). Confluent HUVEC monolayers were then stimulated with human recombinant insulin (from $10^{-6}$ to $10^{-9} \mathrm{~mol} / \mathrm{l}$ ) or human recombinant tumour necrosis factor(TNF)- $\alpha(5 \mathrm{ng} / \mathrm{ml})$ (Genzyme, Cambridge, Mass., USA). After 6 and $16 \mathrm{~h}$, cell lysates were then assayed for luciferase activity using the Promega reporter assay system (Promega, Madison Wis., USA). Luciferase activity was measured in duplicate using a Berthold (Schwarzwald, Germany) model LB9501 luminometer.

Measurements of soluble VCAM-1 concentrations in cell supernatants. Human umbilical vein endothelial cell supernatants $(50 \mu \mathrm{l})$ were taken before and after incubation with insulin (from $10^{-6}$ to $10^{-9} \mathrm{~mol} / \mathrm{l}$ ) for various times up to $24 \mathrm{~h}$. Soluble $V C A M-1$ concentrations were then measured in HUVEC supernatants by ELISA (R \& D Systems, Minneapolis, Minn., USA).

\section{In vivo studies}

This study was conducted in 12 non-insulin-dependent diabetic outpatients ( 8 men and 4 women, mean age $47.1 \pm 7.7$ years) in good metabolic control. The latter was achieved and maintained by diet and glibenclamide, $5 \mathrm{mg}$ twice daily. Exclusion criteria were: age under 25 and over 55 years, pregnancy, use of birth control pills, personal history of cerebrovascular or cardiovascular diseases, concomitant diseases, allergic diatesis, hypertension, obesity, smoking, microalbuminuria, hyperlipidaemia, serum creatinine more than $100 \mu \mathrm{mol} / \mathrm{l}$, overt atherosclerotic lesions, acute recent ( $<3$ months) diseases. A group of 12 healthy volunteers ( 7 men and 5 women, mean age $42.2 \pm 7.2$ years) served as a control.

After informed consent had been given and 2 weeks on a weight-maintaining diet, blood samples for measurements of plasma soluble $V C A M-1$ concentrations were drawn from an antecubital vein. The samples were taken after the subjects had been in a supine position and an intravenous catheter had been inserted in a hand vein for $1 \mathrm{~h}$. The vein was cannulated in retrograd fashion and the catheter kept pervious by saline infusion $(0.2 \mathrm{ml} / \mathrm{min})$. On the same occasion, blood samples for routine haematochemical check, plasma glucose and insulin concentrations were taken.

After baseline blood samplings, non-insulin-dependent diabetic patients and control subjects underwent euglycaemic hyperinsulinaemic clamp studies. Blood samples for plasma soluble $V C A M-1$ concentrations were taken at 60 and 120 min during insulin infusion and then after 60 min recovery. Throughout the test, plasma glucose concentrations were measured at 5-min intervals and maintained at euglycaemic concentrations by a variable infusion of $20 \%$ D-glucose solution.

Plasma soluble VCAM-1 concentrations were assessed by ELISA ( R \& D Systems). Plasma insulin concentrations were assessed by RIA (Ares-Serono, Milan, Italy). Plasma glucose concentrations were measured by the glucose oxidase method.

Statistical analysis. Differences among groups were tested for significance by one-way analysis of variance followed by the Bonferroni's test and the Newman-Keuls test for pairwise comparisons. Multiple comparisons were analysed by the analysis of variance and then by analysis for adjusting the significance level. Linear regression and correlation were used to evaluate relations between variables. Descriptive variables were tested for significance by the chi-squared method. A $p$ 
value less than 0.05 was considered less than significant. All data are means \pm SD. In vitro data represents the mean of four different experiments.

\section{Results}

In vitro data. To determine whether insulin induces a $\mathrm{NF}-\varkappa \mathrm{B}$ driven reporter gene expression, HUVECs were transiently transfected with an NF- $x \mathrm{~B}-\mathrm{lu}-$ ciferase reporter and then treated with increasing concentrations of insulin for 6 or $16 \mathrm{~h}$. Cells stimulated by TNF- $\alpha$ were used as a control.

Insulin induces only a $1.8 \pm 0.3$-fold increase in $\mathrm{NF}-x \mathrm{~B}$ transcription activities in cultured $H U V E C s$ (Fig. 1A). When the effect of insulin on the VCAM-1 reporter gene construct was tested, insulin was unable to induce transcriptional induction of the reporter (Fig.1B). Further, insulin was also unable to increase soluble VCAM-1 concentration in HUVEC supernatants at all times up to $24 \mathrm{~h}$ (Fig. 1C). As expected, TNF- $\alpha$ strongly increased NF- $\varkappa \mathrm{B}$ transcription activities (mean increment: $13.2 \pm 1.4$-fold), VCAM1 reporter gene construct (mean increment: $6.2 \pm 1.0$-fold), and soluble $V C A M-1$ release in $H U$ VEC supernatants (control HUVECs, $220 \pm 15 \mu \mathrm{g} / \mathrm{l}$ after $24 \mathrm{~h}$; TNF- $\alpha$ HUVECs stimulated by: $1375 \pm 95 \mu \mathrm{g} / \mathrm{l}$ after $24 \mathrm{~h}$ ).

In vivo data. The general characteristics of the study group are given in Table 1 . As is shown, non-insulindependent diabetic patients had good metabolic control but had manifested higher fasting glucose $(p<0.0001)$, insulin $(p<0.001)$ concentrations and glycated haemoglobin $(p<0.0001)$ values than healthy subjects.

The baseline concentration of soluble VCAM-1 was higher $(p=0.03)$ in non-insulin-dependent diabetic patients $(708.7 \pm 97.4 \mu \mathrm{g} / \mathrm{l})$ than control subjects $(632.1 \pm 65.2 \mu \mathrm{g} / 1)$. Circulating soluble VCAM-1 concentrations were not related to other variables. No statistically significant changes in plasma soluble $V C A M-1$ concentrations were observed during the clamp studies (Fig.1D).

\section{Discussion}

Our study showed increased circulating VCAM-1 concentrations in adult non-obese, non-dyslipidaemic, normotensive, non-insulin-dependent diabetic patients. It failed to shown, however, any relation between $V C A M-1$ regulatory mechanisms and hyperinsulinaemia. Indeed, although non-insulin-dependent diabetic patients were greatly hyperinsulinaemic, no correlations were found between plasma insulin and soluble $V C A M-1$ concentrations at fast as well as during 2-h euglycaemic insulin infusions. Further, incu-
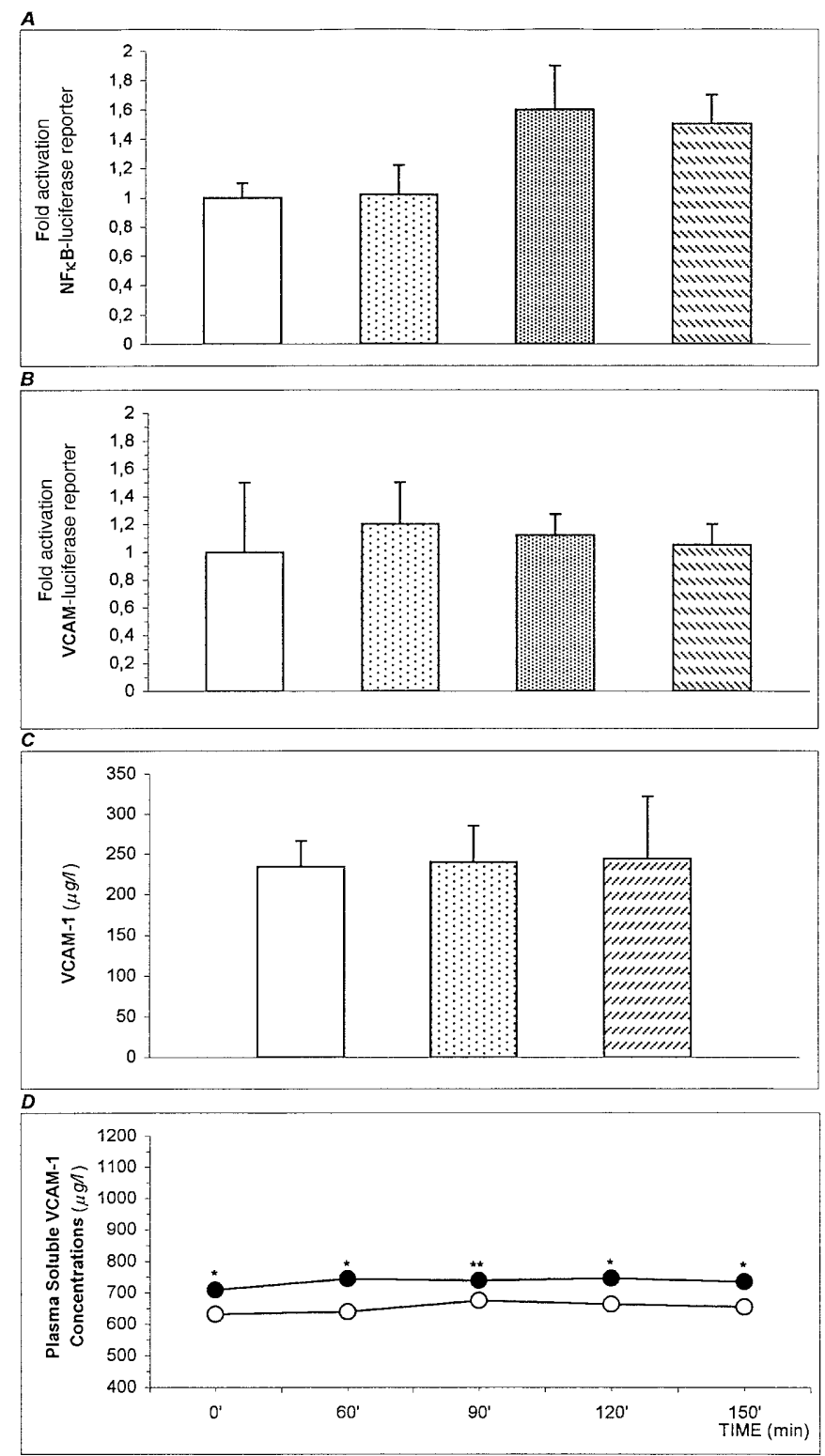

Fig. 1. A Nuclear factor- $\varkappa B$ transcriptional activity modifications after stimulation with insulin. Data are means \pm SD of four different experiments. B Effects of insulin on luciferase activity in cultured human vascular endothelial cells. Data are means \pm SD of four different experiments. C Bars show soluble VCAM- 1 concentration (means \pm SD of four experiments) in supernatants from cultured HUVECs incubated alone or with insulin over 24 h. D Effect of 2-h euglycaemic hyperinsulinaemia on plasma soluble vascular cell adhesion (VCAM)-1 concentrations in 12 non-insulin-dependent diabetic patients and 12 control subjects. Standard deviations were omitted for clarity. At all times, plasma soluble VCAM1 concentrations were higher in non-insulin-dependent diabetic patients than controls $(* \mathrm{p}=0.03 ; * * \mathrm{p}=0.04)$. Panels $\mathrm{A}, \mathrm{B}$ and C: $\square$ control; $\square$ Insulin $10^{-6} ; \square$ Insulin $10^{-7}$; $\$$ Insulin $10^{-9}$; Panel D: non-insulin-dependent diabetic patients $\bigcirc$ control subjects 
Table 1. General characteristics of the study group

\begin{tabular}{|c|c|c|c|}
\hline Variable & $\begin{array}{l}\text { Non-insulin dependent } \\
\text { diabetic patients } \\
(n=15)\end{array}$ & $\begin{array}{l}\text { Control subjects } \\
(n=10)\end{array}$ & $P<$ \\
\hline Sex (male/female) & $8 / 4$ & $7 / 5$ & NS \\
\hline Fasting insulin $(\mathrm{pmol} / \mathrm{l})$ & $138.6 \pm 48.2$ & $87.2 \pm 11.4$ & 0.001 \\
\hline Glycated haemoglobin (\%) & $6.1 \pm 0.3$ & $4.5 \pm 0.7$ & 0.0001 \\
\hline Body mass index $\left(\mathrm{kg} / \mathrm{m}^{2}\right)$ & $24.0 \pm 0.2$ & $23.2 \pm 0.4$ & NS \\
\hline Serum triglycerides $(\mathrm{mmol} / \mathrm{l})$ & $1.6 \pm 0.2$ & $1.4 \pm 0.2$ & NS \\
\hline Systolic blood pressure $(\mathrm{mm} \mathrm{Hg})$ & $118.8 \pm 6.1$ & $115.6 \pm 5.1$ & NS \\
\hline Diastolic blood pressure ( $\mathrm{mm} \mathrm{Hg}$ ) & $79.6 \pm 6.1$ & $78.4 \pm 4.9$ & NS \\
\hline
\end{tabular}

bation of $H U V E C s$ with insulin (from $10^{-6}$ to $10^{-9}$ $\mathrm{mol} / \mathrm{l}$ ) for various times up to $24 \mathrm{~h}$ was not able to increase NF- $x \mathrm{~B}$ and VCAM-1 transcriptional activities and soluble $V C A M-1$ secretion.

Our in vitro data do not completely agree with recent findings showing a 3.5 -fold NF- $x \mathrm{~B}$ induction in Chinese hamster ovary cells after insulin stimulation [5]. Ovary cell transfectants stably overexpressing wild-type insulin receptors were, however, used in that study [5]. Thus, discrepancies between our and previous data [5] simply reflects differences in cellular systems, i.e. in insulin sensitivity between $H U$ $V E C s$ and transfected ovary cells. Accordingly, NF$x \mathrm{~B}$ was not stimulated by insulin in parental, i. e. untransfected and therefore not overexpressing insulin receptors, Chinese hamster ovary cells [5]. Our data seems also to be in contrast with recent data showing that NF- $x \mathrm{~B}$ induced $m d r 1 b$, a membrane-bound Pglycoprotein, expression in rat hepatoma cells stimulated by insulin [7]. After insulin stimulation NF- $x \mathrm{~B}$ alone was not, however, sufficient to induce $m d r 1 b$ transcriptional activation [7]. Thus, other transcriptional factors must be activated by insulin in rat hepatoma cells to induce $m d r 1 b$ transcription.

In our in vivo findings, the increased concentration of circulating soluble $V C A M-1$ indicated that membrane-bound $V C A M-1$ was up regulated and the vascular endothelium was activated in non-insulin-dependent diabetic patients. Despite these latter patients being greatly hyperinsulinaemic, insulin was not responsible for the observed endothelial activation, as indicated by the lack of effects of insulin infusion on plasma soluble $V C A M-1$ concentrations. Consistent with this interpretation, increased plasma soluble $V C A M-1$ concentrations, that were unrelated to fasting insulin concentrations, have already been described in noninsulin-dependent [8] and insulin-dependent diabetic patients [9]. Further, plasma soluble VCAM-1 negatively correlated with intraerythrocytic glutathione concentrations and decreased after $\mathrm{N}$-acetyl-L-cysteine was given orally [8]. Therefore, the current findings support the previous hypothesis [8] that an early up regulation of $V C A M-1$ is present in non-insulin-de- pendent diabetic patients due to increased oxidative stress rather than hyperinsulinaemia.

Our study showns that plasma soluble VCAM-1 concentrations are increased in non-insulin-dependent diabetic patients without complications and in good metabolic control. In addition, we clearly showed that insulin was not able to induce VCAM-1 up regulation in vitro and hyperinsulinaemia was not responsible for the increased soluble $V C A M-1$ release in vivo. Thus, other mechanisms must be active in non-insulin-dependent diabetic patients without complications and these lead to earliest endothelial changes. In this context, circulating concentrations of soluble $V C A M-1$ but not of other endothelial adhesion molecules, i.e. intercellular adhesion molecule-1, E-selectin and P-selectin and thrombomodulin correlated with the extent and severity of atherosclerosis in humans [10].

Acknowledgements. The present work was supported by grants from the Andrea Cesalpino Foundation and the Italian Ministry of University and Scientific Research.

\section{References}

1. Pÿorälä M, Mettinen M, Laakso M et al. (1998) Hyperinsulinemia predicts coronary heart disease risk in healthy middle-aged men:the 22-year follow-up results of the Helinski Policemen Study. Circulation 4(98): 398-404

2. Desideri G, Ferri C, Bellini C et al. (1997) Effects of ACE inhibition on spontaneous and insulin-stimulated endothelin-1 secretion. In vitro and in vivo studies. Diabetes 46: $81-86$

3. O'Brien KD, Allen MD, McDonald TO (1993) Vascular cell adhesion molecule-1 is expressed in human coronary atherosclerotic plaques. Implication for the mode of progression of advanced coronary atherosclerosis. J Clin Invest 92: 945-951

4. Neish AS, Read MA, Thanos D et al. (1995) Endothelial interferon regulatory factor- 1 cooperates with $\mathrm{NF}-x \mathrm{~B}$ as a transcriptional activator of vascular cell adhesion molecule-1. Mol Cell Biol 15: 2558-2569

5. Bertrand F, Atfi A, Cadoret A, et al. (1998) A role for nuclear factor- $x \mathrm{~B}$ in the antiapoptotic function of insulin $\mathrm{J}$ Biol Chem 273: 2931-2938 
6. Gearing AJH, Newman W (1993) Circulating adhesion molecules in disease. Immunol Today 14: 506-512

7. Zhou G, Kuo T (1997) NF- $x$ B-mediated induction of mdr1 $\mathrm{b}$ expression by insulin in rat hepatoma cells. $\mathrm{J}$ Biol Chem 272: 15174-15183

8. De Mattia G, Bravi MC, Laurenti O et al. (1998) Reduction of oxidative stress by oral $\mathrm{N}$-acetyl-L-cysteine treatment decreases plasma soluble vascular cell adhesion molecule-1 concentrations in non obese, non-dyslipidemic, normotensive patients with non-insulin-dependent diabetes. Diabetologia 41: 1392-1396
9. Fasching P, Veitl M, Rohac M et al. (1996) Elevated concentrations of circulating adhesion molecules and their association with microvascular complications in insulin- dependent diabetes mellitus. J Clin Endocrinol Metab 81: 4313-4318

10. Peter K, Nawroth P, Conradt C et al. (1997) Circulating vascular cell adhesion molecule-1 correlates with the extent of human atherosclerosis in contrast to circulating intercellular adhesion molecule-1, E-selectin, P-selectin and thrombomodulin. Arterioscler Thromb Vasc Biol 17: $505-512$ 